\title{
IGF-methotrexate Conjugate
}

National Cancer Institute

\section{Source}

National Cancer Institute. IGF-methotrexate Conjugate. NCI Thesaurus. Code C113789.

A conjug ate containing the antimetabolite and antifolate agent methotrexate conjug ated to insulin-like growth factor (IGF), with potential antineoplastic activity. After intravenous administration, the IGF moiety of the IGF-methotrexate conjug ate binds to and is internalized by IGF receptors (IGFR) on the surface of tumor cells. Following cell entry, the methotrexate then binds to and inhibits the enzyme dihydrofolate reductase, which catalyzes the conversion of dihydrofolate to tetrahydrofolate. This results in both the inhibition of DNA and RNA synthesis and the induction of death in rapidly dividing cells. Binding to IGFR can localize the cytotoxic effect of methotrexate in tumor cells. This may increase its efficacy while decreasing its toxicity to normal, healthy cells. IGFR is overexpressed on many types of cancer cells and has been implicated in metastasis and resistance to apoptosis. 